the non-specialist. The process of gluconeogenesis is of interest to biochemists because it provides excellent examples of the numerous types of metabolic regulatory mechanisms which uperate in vivo; $\mathrm{H}$. A. Lardy gives a concise account of current views in this rapidly moving field.

The publication of reports of lectures delivered before the Harvey Society of New York is valuable in providing authoritative accounts of topics in medical sciences. It scarcely seems necessary, however, to make non-members pay for more than forty pages doaling with Society business and membership.

D. G. WALKER

\section{NUTRITIONAL BIOCHEMISTRY}

\section{Newer Methods of Nutritional Biochemistry with} Applications and Interpretations

Vol. 2. Edited by Anthony A. Albanese. Pp. xiii +558 . (New York: Academic Press, Inc.; London: Academic Press, Inc. (London), Ltd., 1965.) $148 s$.

As the knowledge of nutrition expands the dependence of clinical and biological research on biochemical methods increases. The first volume of this series clearly indicated the value of critical reviews of methods of nutritional biochemistry. The new volume is a detailed discussion of biochemical procedures applicable to nutrition research in ten areas of special interest.

In the opening chapter Dr. Pearson of Michigan State University collects the newer methods of measuring body composition; this is one of the most important problems underlying all studies of nutrition. Both direct and indirect methods are reviewed and discussed in relation to human and animal physiology. A chapter on energy metabolism by Dr. Passmore and Dr. Draper of tho University of Edinburgh follows, and brings up to date information on the most basic nutritional requirement for calories. The correlation between endocrinological factors and nutrition is shown in chapters on growth and pituitary hormones, on anabolic steroids and on calcium and phosphorus metabolism. Three further chapters are concerned with utilization of essential amino-acids by man, with "abnormal metabolites" of amino-acid origin, and with enzymes of the tryptophan-nicotinic acid pathway. The water soluble vitamins, folic acid, biotin and pantothenic acid are given a chapter and so are the fat soluble vitamins, $\mathrm{A}, \mathrm{D}, \mathrm{E}$ and $\mathrm{K}$.

Every chapter contains useful information on many aspects of these problems other than the biochemical methods of assessment. Recent international recommendations on vitamin nomenclature are included together with details of structure, propertios and enzyme connexions as well as methods of assay by chemical, biological and microbiological methods. The documentation for all subjects is excellent and the arrangement of the author index is particularly valuable.

The editorial epilogue surveys the value of biochemical approaches to nutritional problems with the final counsel that biochemical studies should be constantly encouraged in order to obtain data of the utmost fundamental and practical usefulness.

A. M. Copping

\section{MUSCLE}

\section{Muscle}

Proceedings of the Symposium held at the University of Alberta, June 1-4, 1964. Edited by W. M. Paul, E. E. Daniel, C. M. Kay and G. Monckton. Pp. xv +584 . (Oxford, London and Now York: Pergamon Press, Ltd., 1965.) $105 s$.

THrs book contains papers given at a symposium on muscle held at the University of Alberta in June 1964. A very wide range of topies is covered and for this reason the papers have been grouped in a number of sections.

The first two sections deal with some of the more basic recent research on striated and smooth muscle and have been given the titles "Muscle Structure and Function" and "Divalent Ions and Muscle Function". H. E. Huxley, C. E. Challice and R. I. Birks contribute well illustrated papers on the structure of striated and cardiac muscle, and certain aspects of the muscle proteins involved in contraction are dealt with by S. V. Perry, A. Stracher, C. M. Kay, W. H. Johnson and A. G. Szent-Györgyi. The energetics of muscular contraction and the part played by ATP are discussed in papers by W. F. H. M. Mommaorts and R. E. Davies. The extremely interesting relationships between the amount of work performed and the amount of "high energy" phosphate used are described and Davies discusses the evidence which he and his collaborators have obtained that the splitting of ATP is, in fact, the primary energy yielding reaction in contraction. $\mathrm{He}$ also deals with the reduction in the amount of "high enorgy" phosphate split when active muscle is passively stretched. It is now known that calcium plays a part in muscular contraction, and various aspects of its role in the contraction of skeletal muscle are considered by R. J. Podolsky, G. B. Frank, W. G. Nayler and by J. G. Foulks and F. A. Perry. The part played by phosphorylase and phosphorylase kinase in cardiac muscle is discussed by G. I. Drummond, J. R. E. Valdares and L. Duncan.

The role of calcium is explored further in the third section under the title "Role of Calcium in Smooth Muscle Function". This section contains papers by P. J. Goodford, J. M. Marshall, L. Hurwitz, W. H. Waugh, J. A. M. Hinke, E. E. Daniel and by A. H. Briggs and H. B. Hannah. The title of the fourth section is "Regulation of Smooth Muscle Activity in vivo", and R. CaldeyroBarcia, C. H. Hendricks and G. W. Theobald contribute papers on various aspects of the activity of uterine muscle. The fifth section, which has the title "Nouromuscular Transmission", consists of three papers, the first by D. Elmqvist, W. W. Hofmann, D. M. J. Quastel, S. Thesleff and J. Zelená, tho second by W. L. Nastuk and A. J. Gissen, and the third by R. I. Birks and M. W. Cohen.

Those whose interests tend to lie in the areas of muscle research covered by the earlier sections should find the final section, "Muscle Structure and Function in Disease", most stimulating. It directs attention to some of the clinical implications of work on muscle. The histology, gonetics, electromyography and enzymology of certain muscle disorders are discussed with an emphasis on Duchenne muscular dystrophy. The papers in this section are by C. M. Pearson, C. Coërs, J. V. Basmajian, E. H. Lambert, J. N. Walton, C. J. Nichol, E. Bajusz, G. Jasmin and by E. G. Murphy, M. W. Thompson, P. N. J. Coreyand P. E. Conen.

The particular virtue of this symposium is its broad. ness of outlook. It enables those with specialized interests in muscle to get these into porspective, while it directs the attention of the more general reader to the many faseinating problems which are being explored in contemporarv muscle research.

P. C. Caldwell

\title{
The Living Races of Man
}

\section{HUMAN VARIETY}

By Carleton S. Coon and Edward E. Hunt. Pp. $344+x x+$ 180 plates. (London: Jonathan Cape, 1966.) 70s. net.

THIs book is a sequel to C. S. Coon's The Origin of Races (1963), a book which succeeded in provoking a lively debato, and had the misfortune to be used by racists for their nefarious purposes. The present work is unlikely to have either that kind of success or misfortune. Dr. 